\title{
Modelling of Library System using Agent Goal Decision Information Model: A Case Study
}

\author{
Deepinti Yadav \\ University School of Information and \\ Communication Technology
}

GGSIPU, Dwarka

\author{
Jaspreeti Singh \\ University School of Information and \\ Communication Technology \\ GGSIPU, Dwarka
}

\begin{abstract}
Data Warehouse (DW) is defined as integration of heterogeneous data into multidimensional repository for providing decisional support. Requirement Analysis has played a main role in the development of DW which provides strategic information to the end-users. There are many approaches for elicitation of requirements in the DW. One of the approaches is Agent Goal Decision Information (AGDI) model. In this paper we have discussed about the Agent Goal Decision Information Model and illustrated it with the help of Library Management System.
\end{abstract}

\section{Keywords}

Data Warehouse, Requirement Engineering, AGDI model

\section{INTRODUCTION}

A DW is defined as a subject, integrated, time- dependent and non- volatile collection of summarized and historical data which provides strategic information. DW helps in data navigation, analysis of data and visualizing data in terms of business process using OLAP query processing [1]. DW is a common source for analysis of data which provides on support for decision making processes [2]. DW is multidimensional model and is used to store historical, cleansed, validated, transformed data. A multi- dimensional structure stores the information in form of facts and dimensions. A fact contains the attributes of a business process while dimensions describe the way we analyze a fact in multidimensional structure [3].

Requirement Engineering is considered as the most essential activity of the Software Engineering process. Requirement capture is known to be a critical phase which deals with technical knowledge, organizational, managerial, economic and social issues of the software development [4]. Therefore much emphasis and attention needs to be paid in the early stages of software development. The emerging understanding should be that we should include business models in describing how the intended system should function [5]. As in [5] there are two phases of requirement engineering: early phase and late phase requirements engineering. Early phase activities include how system work intended, how system should meet organizational goals, why system is required, what alternatives are available for stakeholders and how to address stakeholders' interests and concerns [4]. Late requirements include the functional and non- functional of the intended system and which alternative best supports the system-to-be. The late requirements activities deal with completeness, consistency and automated verification of requirements [5].
The main hindrance to the model of a DW system is that it should be precise and user-friendly. Therefore, there is a need of requirements engineering in DW. The objectives of DW are: The DW must contain data contents which help in decision-making capability of DW. This has to be kept in mind while developing the DW. There are different techniques for Requirement Engineering in DW.

The first technique is a Requirement-driven approach which uses the process of CADWA [6]. In the CADWA process, requirements are collected using a goal-based approach, then the DW fragment are designed by selecting Data Marts according to modeling of goals and lastly by integrating all model fragments into DW model.

Another technique for Requirements Engineering is Use Case Driven Approach [3]. In this technique the use case model describes the business processes to be analyzed and then information is provided to DW user and staff. The use case model specifies the roles of DW users and the business processes to be analyzed. The object model gives a clear picture about the structure of internal use case, knows about the analysis capabilities of process and describes the analysis requirements of various actors.

The technique based on business object is proposed in [1] called Business-Object Based Approach. In this a Business Object model is used where the business object is a conceptual object which describes and represents a business concept with an identity. The business object describes identity, domain and behavioural features. The domain features comprises of structural and non-functional features of the domain. The behaviour tells about the activities which the business object is capable of performing with the other business objects. The primary aim is to capture business semantics with common idea which can be used by different parts and participants of business. Business- Object model consists of concepts and contexts belonging to business domain.

A technique based on goals is proposed in [7] called Goal Decision Information (GDI) model. In this model there are three components: Goal, Decision and Information. Goal is defined as aim/objective to be met. An active component is needed to realize the goal which is set. This active component is the decision. The decision is selected for implementing one or more actions to be performed. Information is the specification of data which is stored in DW.

The paper is divided into following 3 sections. Section 2 describes the concept of AGDI model. Section 3 describes the modeling of Early and Late Requirements using the AGDI model which describes the three inter-related modeling activities. Section 4 describes the Case Study of the AGDI model which illustrates the working of AGDI model using the Library Management System. 


\section{AGENT- GOAL- DECISION- INFORMATION MODEL}

In the Agent-Goal-Decision-Information (AGDI) model [8], modeling of stakeholders' interests is done by agent dependencies. An agent depends on other agents for achieving goals, suggesting decisions and providing information. These three dependencies are shown by goal, decision and information dependencies. Early and late requirements are captured using three interrelated modeling activities i.e. organization modeling, goal modeling and decision modeling. The concepts related to AGDI model is described below.

\subsection{Agents}

Agent is defined as the one who represents the stakeholders of organization [9]. There are different types of agents: Internal, external, simple and complex. The internal agent models the internal stakeholders of the organization while the external agents model the external stakeholders. The complex agents may contain simple agents or complex agents. The external agents provide various informational resources to organizational agents to regulate the decisional activities in the organization. It represents end-users, stakeholders, decision makers and users of organization.

\subsection{Agent \& Goal}

Goals are used for identifying, organizing and justifying system requirements [10]. Goals are viewed as objectives of agents to be achieved by the organization [11]. Goals help in requirement elicitation for developing DW. Goals can be simple or complex. Complex goal can further comprise of complex goals or simple goals. An agent may achieve goal on its own or may depend on other agents for the achievement of the same. The first agent is shown by the 'achieves' relationship while the second agent is shown by 'delegate' relationship. The purpose of goals is to carry out decisional activities of the organization. Therefore, they are known as decisional goals [12].

\subsection{Agent, Decision \& Information}

Once the goal is set, we need an active component to realize it. The active component is known as decision. Agents suggest relevant decisions for the achievement of goals. The information required to support the decision is shown by 'provides' relationship. An agent depends or may depend on other agents for required information to support the decision. The decision taken by agents should help in achievement of goals which is shown by 'influence' relationship. The implementation of goals is achieved by set of actions taken by agent, which is shown by the 'associated' relationship.

The AGDI model is used to carry out various modeling activities to capture the early and late requirements for a DW to provide decisional support in the organization.

\section{EARLY \& LATE REQUIREMENT MODELING BY AGDI MODEL}

In the previous section three inter-related modeling activities i.e. organization modeling, goal modeling and decision modeling were mentioned. The entities of these activities i.e. agent, goal, decision and information are represented as oval, rounded rectangle, rectangle and hexagon respectively. Organization and decision modeling is used for modeling early requirements while information modeling is used to model late requirements for DW.

\subsection{Organizational Modeling}

Organizational modeling focuses on the organizational prospect of DW and identifies the agents and their goals [13, 14]. An agent may achieve goal on its own or may depend on other agents for the achievement of goal. It may collaborate or delegate with other agents to achieve specific goal. The output of organization modeling is represented as organization model with the agents and their dependencies. The organizational model is refined till all the complex goals are converted to simple goals which are delegated to other agents. The refined organizational model acts as input to decision modeling activity.

\subsection{Decision Modeling}

In decision modeling, the agents make necessary decisions for achievement of the goals of the agents. The decision can be simple or complex. Complex decisions can be refined into simple decisions by agent interaction among themselves. The decision modeling focuses on how the stakeholders fulfil their objectives. The organizational and decision model captures the 'whys' of the system requirements or the early requirements. The decision modeling is represented by agents and their decision dependencies among them. The output of decision modeling is given to information modeling activity.

\subsection{Information Modeling}

In information modeling, agents capture the information to support various decisions made in the decision modeling. The information which is identified in the information modeling is available for DW. This information identifies the 'what' of the DW system or the late requirements of a DW. The information model depicts agents and their information dependencies to support a particular decision.

\section{CASE STUDY OF AGENT GOAL DECISION INFORMATION MODEL}

In the case study an example of a Library System of a reputed university is taken and AGDI model is applied on it to derive the information required to model the requirements needed for DW and then we use the modeling activities to determine the early and late phase requirements of the DW.

Library is the most important part of any university. The library is run by Librarian along with the staff presided over with head of staff, technical staff presided with head of technical staff. The library is accessed by the students, teachers, staff, technical staff and librarian of the university. The library is funded by the funding agencies like the university fund and fund provided by the various publishers. The library is regulated by the Library Committee which regulates the various activities in the library. We perform various modeling activities to capture the early and late requirements to support the decisions made by the library through organization, decision and information modeling activities which is discussed in the following sub- sections.

\subsection{Organization Modeling}

In this model various stakeholders of the library system and their goals are identified as agents. The Library is taken as the complex agent whereas staff, technical staff is identified as internal agents. Students, teachers, regulatory and funding agencies are external agents for the library system. The library can achieve the goal to 'maintain books' while the regulating agency will achieve the goal of 'follow rules and regulations'. The library funding agency will provide the funds to the library. When the agent/goal is complex it has to be converted to simple agent/goal. Library being a complex agent can be 
broken down to simple agent as 'Librarian' who achieves goal by collaborating with the Library. The Librarian main job is to 'Maintain books' which is a complex goal. The agent then breaks down this complex goal into simpler ones: 'Improve Standards', 'Academic Growth' and 'Hire efficient staff'. As all these sub goals are important for achieving the goal to 'Maintain books' so it is connected using the 'and' link. This refining of goals is done till the entire complex agents/goals are converted to simpler ones.

The goal 'Hire efficient Staff' can be delegated to 'creating welfare policies' who acts as an agent to 'Head of Staff'. The simple organizational model and the organizational model depicting the new agents and their goal dependencies is shown below in figures 1 and 2

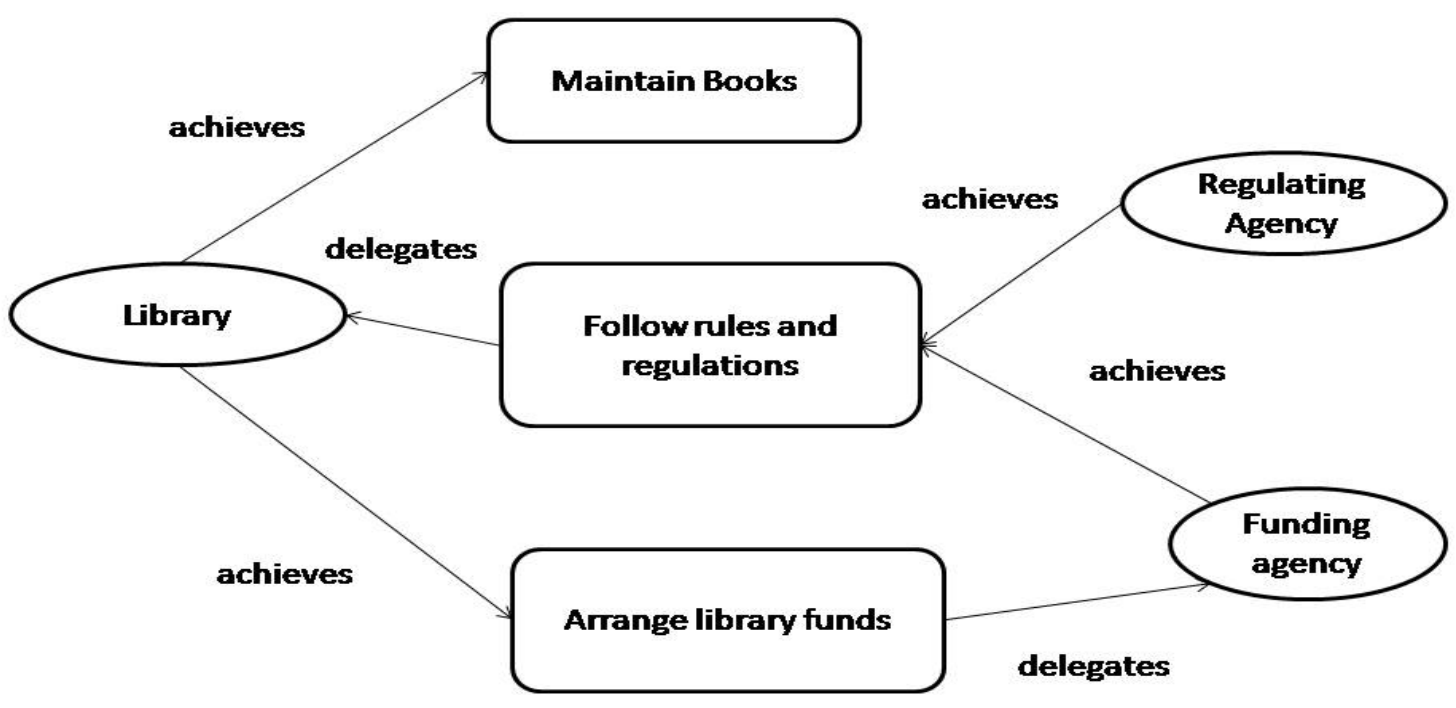

Figure 1: Organizational Model for Library- showing agents and dependencies

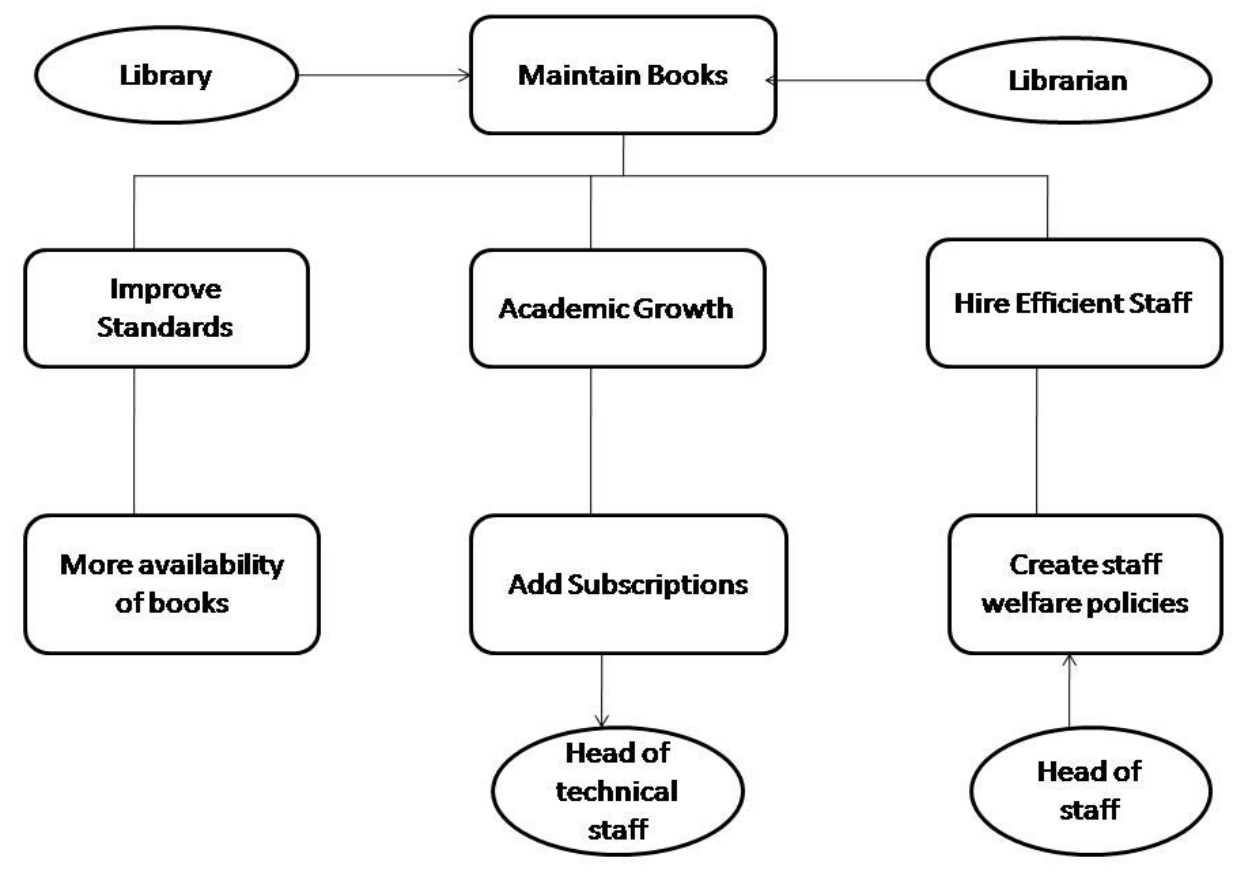

Figure 2: Simplified Organizational Model for Library- showing new agents and their goal dependencies.

\subsection{Decision Modeling}

During decision modeling, the agent suggests different decisions that are required to be taken for the goal of the agent. Now decisions can be simple or complex. Complex decisions can be simplified into simple decisions.
In view of the simplified organizational model, we can implement 'Improve Standards' as goal by agent 'Staff' as shown in figure 3. To achieve these goals, the following decisions need to be taken by the agent 'Staff':

a) Select Courses of university 


\section{b) Constitute Search Committee \\ c) Update books}

The decisions a) and c) are simple decisions which are delegated to Staff and Head of Staff respectively. But the decision b) is complex decision which is refined by two decisions 'Books required in specific field' and 'Books available in fields'. As both the decisions are necessary they are linked by 'and' link.

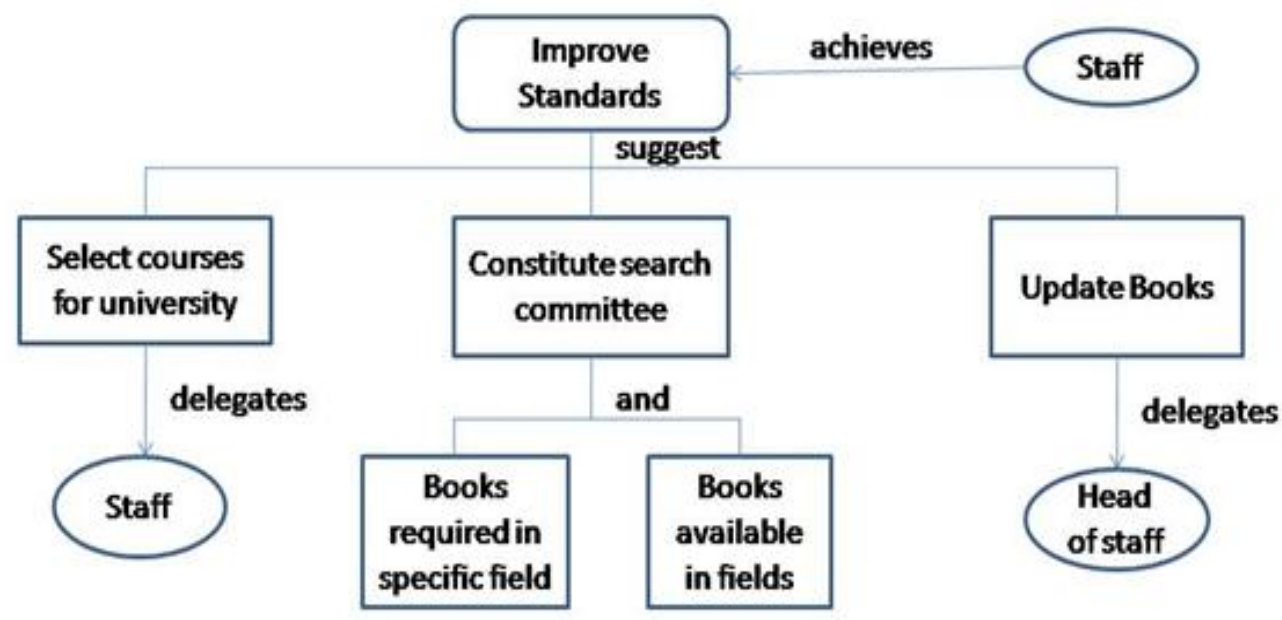

Figure 3: Decision Model showing agents and decision dependencies to achieve goal 'Improve Standards'

Similarly for achieving the goal 'Hire efficient staff' the agent 'Head of Staff' takes the following decisions as shown in figure 4:

a) Make rules and regulations

b) Post an advertisement c) Test and interviews

d) Recruit the staff

e) Provide efficient training

Here all the decisions are simple decisions.

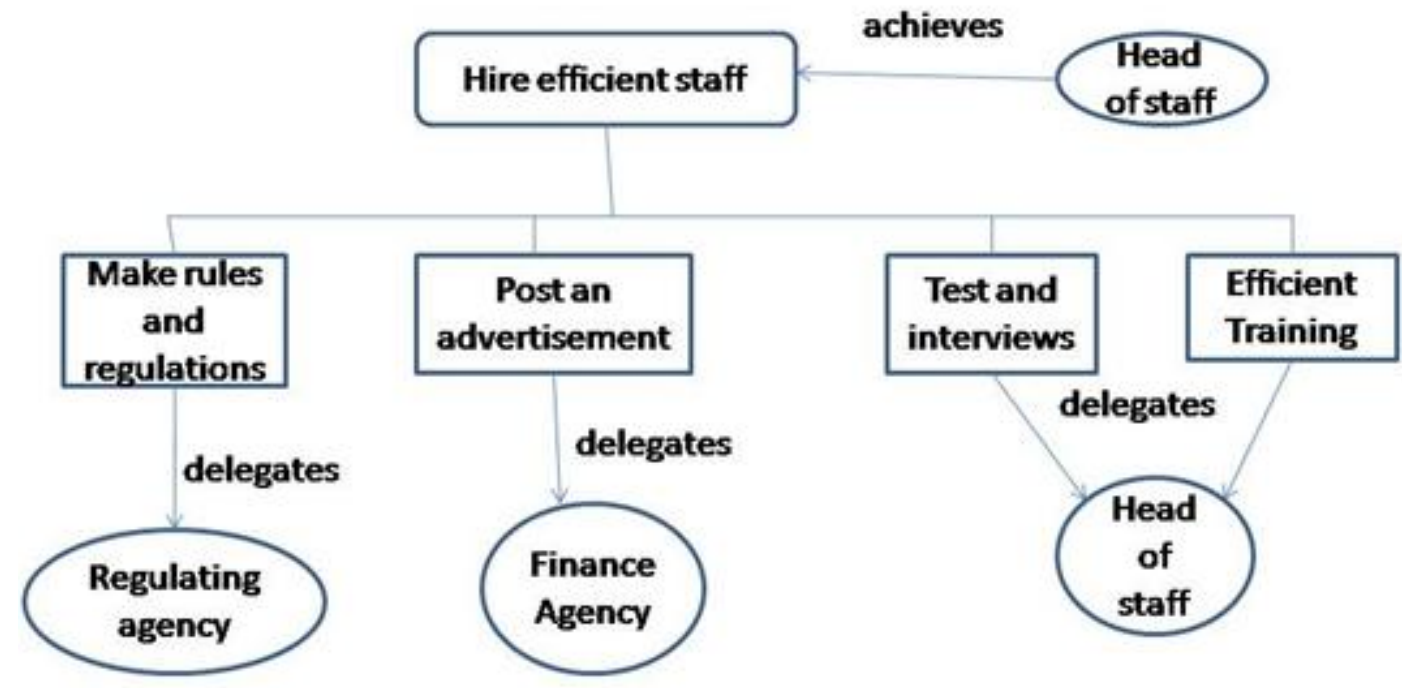

Figure 4: Decision Model showing agents and their decision dependencies for achieving goal 'Hire efficient staff'

Similarly the goal 'Add subscriptions' can be decided by agent 'Technical Staff' which takes the following decisions as shown in figure 5:
a) Analyze the present decisions
b) Get Experts Opinion

c) Set Up New Subscriptions

d) Login into new subscriptions

e) Create account in the subscriptions

Here also all the decisions are simple decisions. 


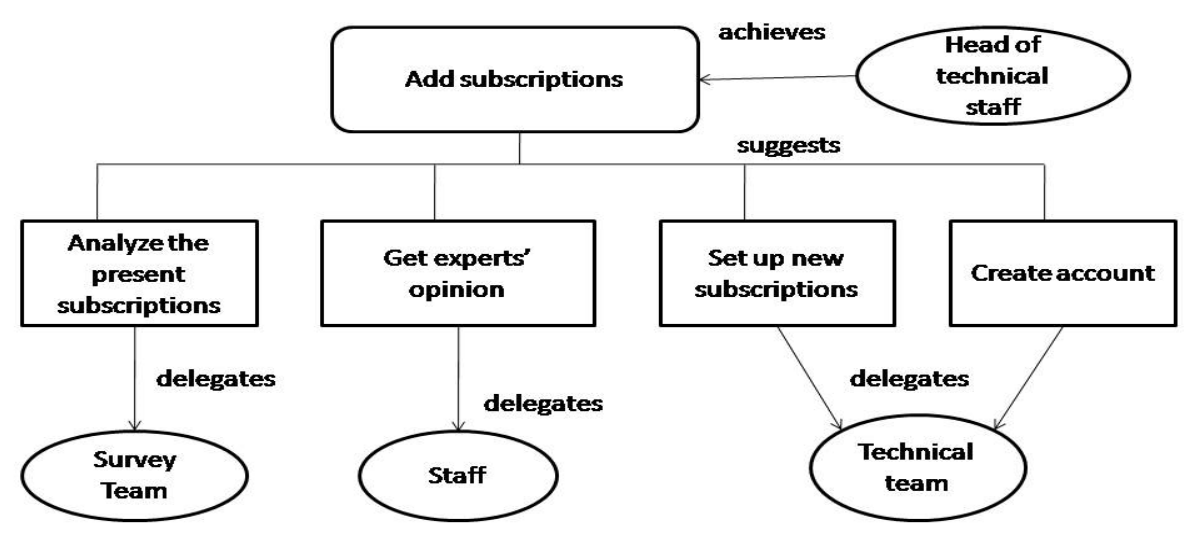

Figure 5: Decision Model showing agents and their decision dependencies for achieving goal 'Add subscriptions'

\subsection{Information Modeling}

During information modeling, agents identify the information to support the decisions made by the agents. The information captured during information modeling may be available for DW to support the decisions. For example, to support the decision 'Select courses of university' the information required for agent 'Staff' are:

a) Courses in the University

b) Subjects in the courses

\section{c) Library Committee}

All the information mentioned in a), b) and c) is delegated to various agents 'Staff', 'Dean' and 'Funding Agency' respectively. The information provided in a) can be provided by 'Check website' or 'Check brochure'. The information provided in b) can be provided by 'Duration' and 'Teachers'. The information provided in c) can be provided by 'Available books' and 'New books'.

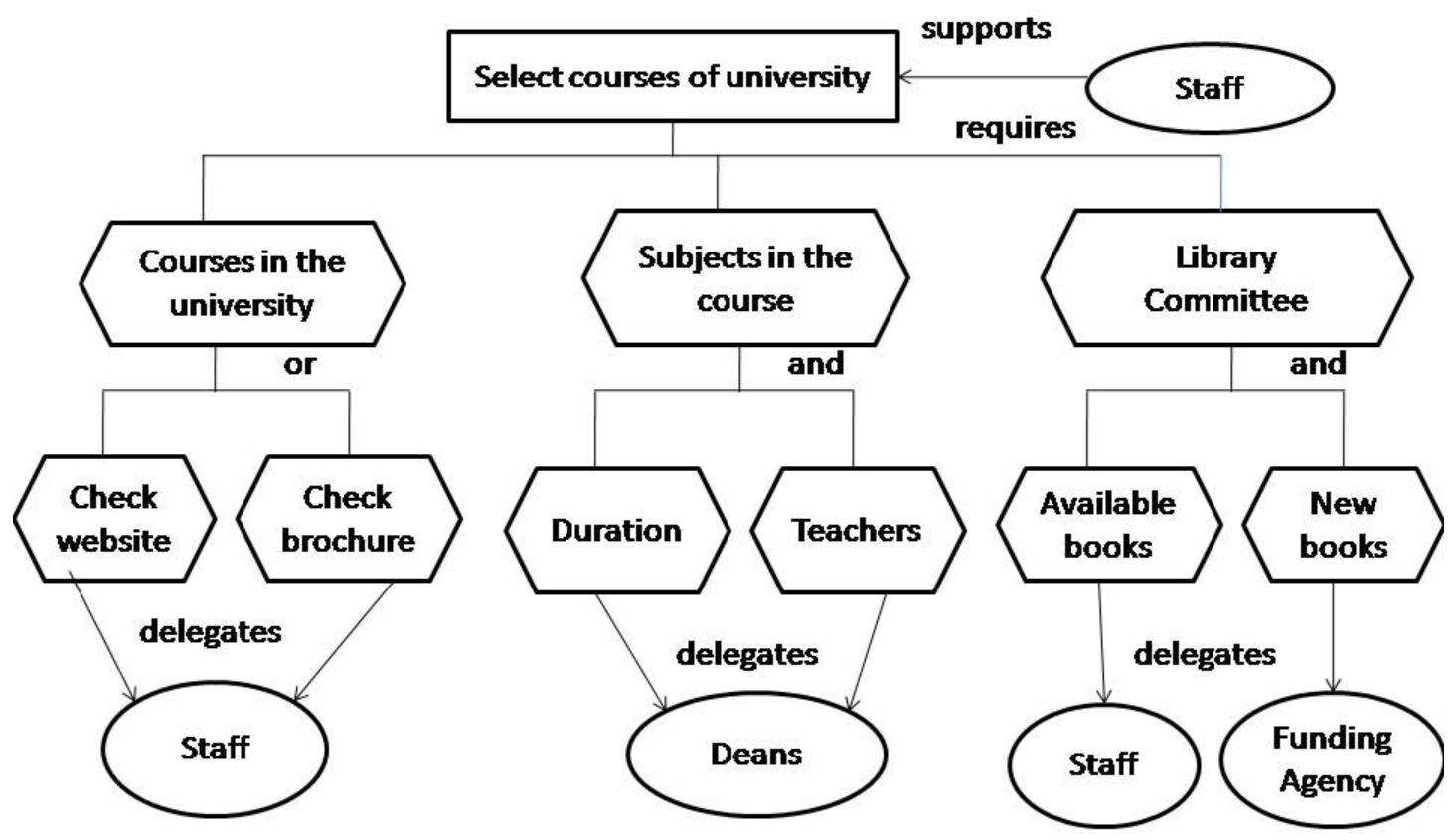

Figure 6: Information Model showing agents and their information requirements for achieving decision 'Select courses of University'

Similarly the decision 'Makes rules and regulations' the information required by agent 'Regulating Agency' are as shown in figure 7 :
a) Make a selection committee
b) List norms in selection board
c) List external academic experts

The information mentioned in a), b) and c) is delegated to the agents 'Registrar', 'Staff' and 'Other universities' respectively. The information in a) is provided by 'qualification needed' and/or 'experience needed'. The information in b) is provided by 'qualification wise' and/or 'experience wise'. 


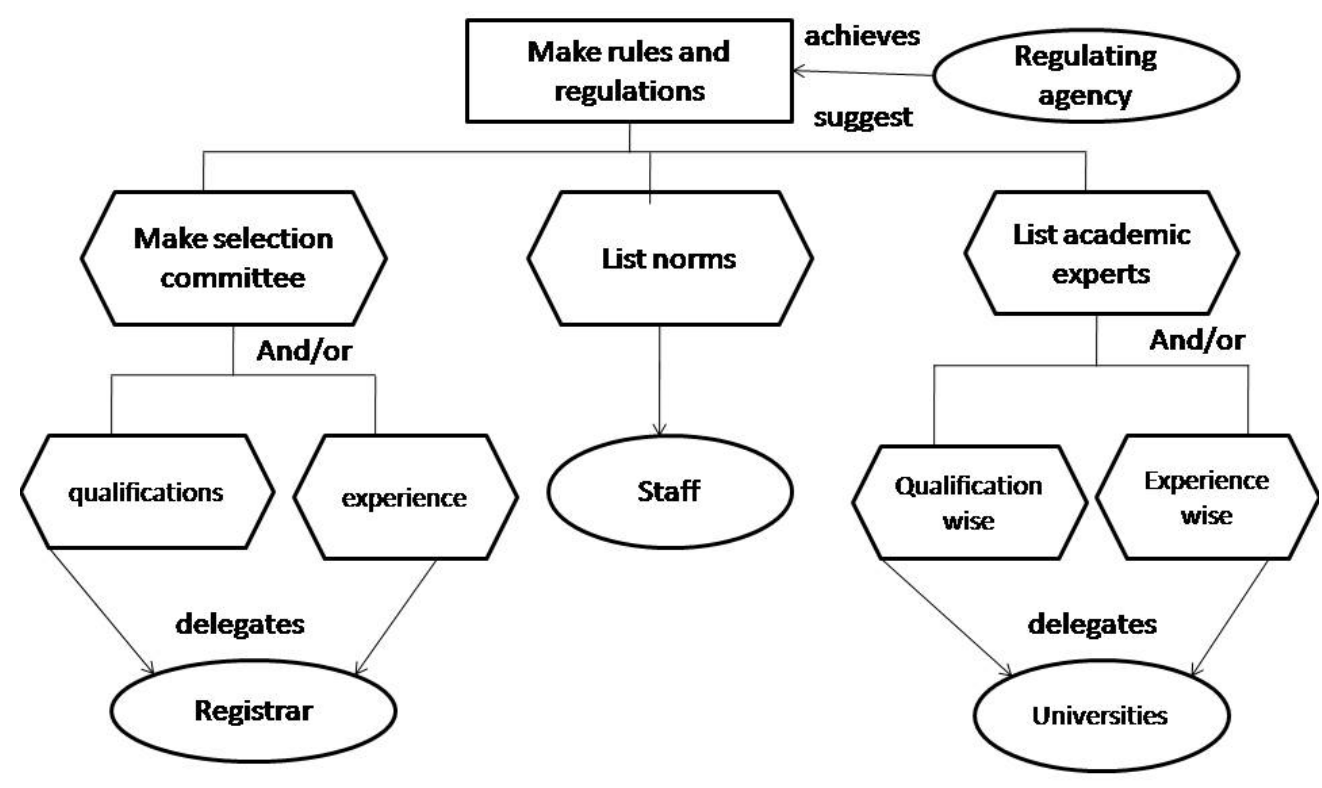

Figure 7: Information model showing agents and information required for fulfilling decision 'Make rules and regulations'

With the help of Library Management System we have elicit the early and late requirements using the AGDI model and its three inter- related modeling activities i.e. organization, decisional and informational modeling.

Table 1 describes the agent, goal, decision and information identified for Library Management System using AGDI model

Table 1: Different entities of AGDI model

\begin{tabular}{|c|c|c|c|}
\hline S.No & $\begin{array}{l}\text { Model } \\
\text { entities }\end{array}$ & $\begin{array}{c}\text { Types of } \\
\text { model entities }\end{array}$ & $\begin{array}{c}\text { Name of the } \\
\text { entities }\end{array}$ \\
\hline \multirow[t]{4}{*}{1} & \multirow{4}{*}{ Agent } & Simple agent & Librarian. \\
\hline & & Internal agent & $\begin{array}{l}\text { Staff, technical } \\
\text { staff, deans, } \\
\text { registrar, head of } \\
\text { staff \&technical } \\
\text { staff. }\end{array}$ \\
\hline & & External agent & $\begin{array}{c}\text { Regulating } \\
\text { agency, funding } \\
\text { agency, students, } \\
\text { teachers. } \\
\end{array}$ \\
\hline & & $\begin{array}{c}\text { Complex } \\
\text { agent }\end{array}$ & $\begin{array}{c}\text { Library, } \\
\text { universities. }\end{array}$ \\
\hline \multirow[t]{2}{*}{2} & \multirow[t]{2}{*}{ Goal } & Complex goal & $\begin{array}{l}\text { Maintain books, } \\
\text { follow rules and } \\
\text { regulations, } \\
\text { arrange library } \\
\text { funds. } \\
\end{array}$ \\
\hline & & Simple goal & $\begin{array}{c}\text { Improve } \\
\text { standards, } \\
\text { academic growth, } \\
\text { hire efficient } \\
\text { staff, more } \\
\text { availability of } \\
\text { books, add } \\
\text { subscriptions, } \\
\text { create staff } \\
\text { welfare policies. }\end{array}$ \\
\hline 3 & Decision & $\begin{array}{l}\text { Complex } \\
\text { decision }\end{array}$ & Constitute search \\
\hline
\end{tabular}

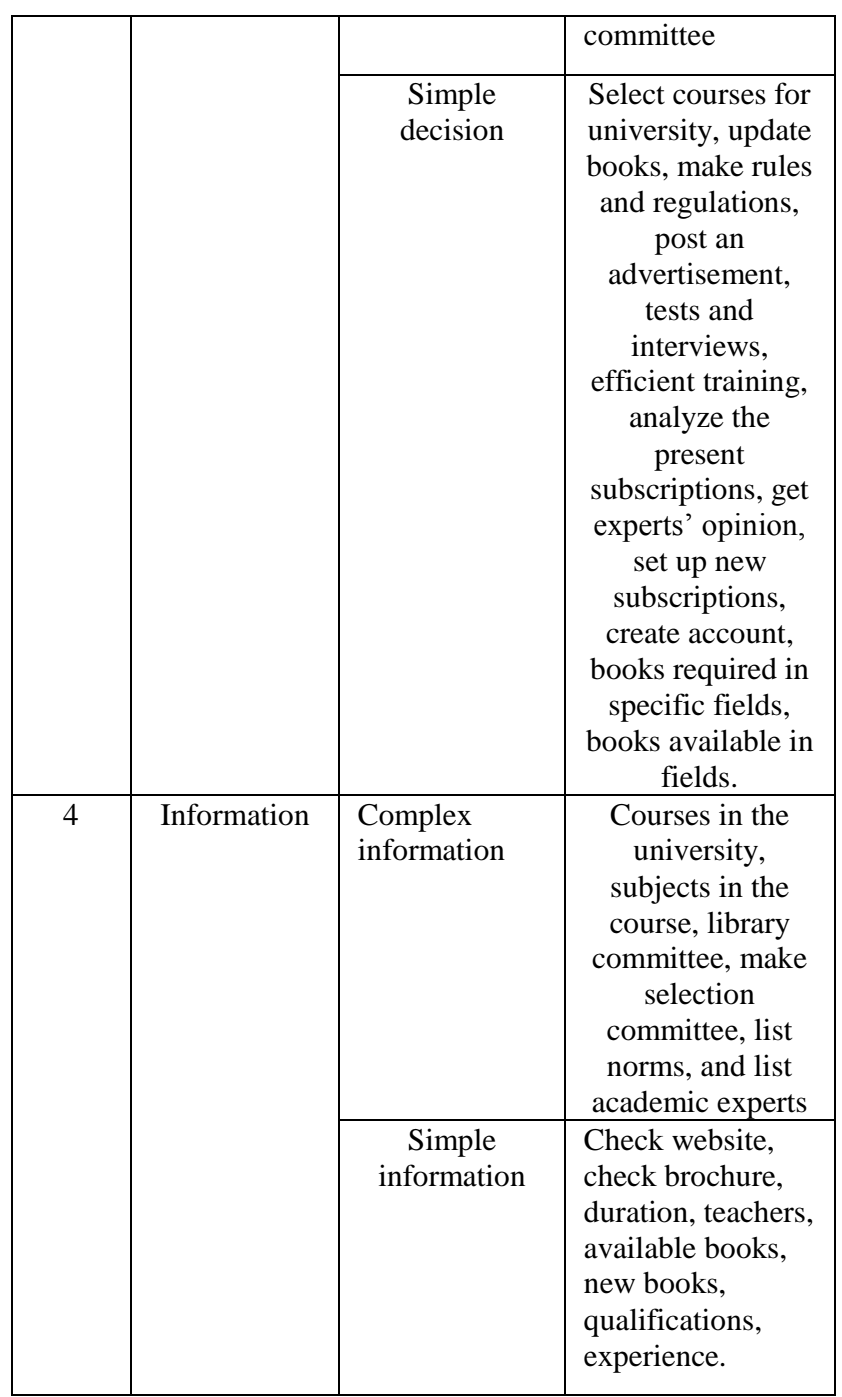




\section{CONCLUSIONS}

In this paper, a case study of Library system is taken to demonstrate the use of a remarkable technique of Requirement Engineering in DW that is, 'Agent Goal Decision Information' model. The various DW requirements engineering approaches which were introduced previously have not been able to distinguish between early and late requirements engineering phases. In this AGDI model the stakeholders and end users of organization are identified and dependencies and associations between the stakeholders are modeled for achieving the goals which helps in capturing the early and late requirements of DW. The elicitation of early and late requirements in AGDI model is done by the modeling activities i.e. organizational modeling, decisional modeling and informational modeling. The early requirements of DW are captured by organizational and decisional modeling activities while late requirements of DW are captured by informational modeling activity.

In this paper the working of AGDI model using the Library Management System is illustrated. The agents of this system are Librarian, Staff, Head of Staff, technical staff, Deans, Universities, etc. The goals of this system are Maintain Books, Follow rules and regulations etc. The decisions of this system are Select Courses of university, Constitute Search Committee, Get Experts Opinion, Set Up New Subscriptions, Login into new subscriptions etc. The information of this system are Check website, Check brochure, Available books, New books etc.

\section{ACKNOWLEDGEMENTS}

I would like to give sincere thanks to honourable guide Ms. Jaspreeti Singh and others who have contributed towards the preparation of the paper. I would like to thank all the faculties of USICT and university resource available to us for their support and contribution.

\section{REFERENCES}

[1] Sarkar Anirban, 'Data Warehouse Requirements Analysis Framework: Business- Object Based Approach', International Journal of Advanced Computer Science and Applications, Vol. 3, No. 1, 2012

[2] M. Sandeep, S. Girish, Soni A. K., 'Requirement Elicitation Techniques for Data warehouse Review Paper', International Journal of Emerging Technology and Advanced Engineering, Volume 2, Issue 12, December 2012

[3] List, B., Shiefer, J., Tjoa, A.: Process-oriented requirement analysis supporting the DW design process - a use case driven approach. In: Ibrahim, M., Küng, J., Revell, N. (eds.) DEXA 2000. LNCS, vol. 1873, pp. 593-603. Springer, Heidelberg (2000)

[4] F. M. R. Alencar, J. Castro, G. A. C. Filho, and J. Mylopulous, "From Early Requirements Modeled by the i* technique to Later Requirements Modeled in Precise UML, in WER, pages 92-108, 2000.

[5] Dubois, E., Yu, E., Petit, M.: From Early to Late Formal Requirements: a Process-Control Case Study, Proceedings of the 9th international workshop on Software specification and design, Ise- Shima, Japan. IEEE Computer Society(1998) 34-42

[6] Gam, I., Salinesi, C.: A requirement-driven approach for designing DWs. In: REFSQ (2006)

[7] Prakash N., Gosain A., "A Requirements Engineering for DW Development". Proceedings of CAiSE03 Forum, 2003.

[8]M. Kumar, A. Gosain and Y. Singh, "Stakeholders Driven Requirements Engineering Approach for DW Development," Journal of Information Processing Systems, Vol. 6(3), pp. 385-402, 2010.

[9] Hewitt, C., Viewing Control Structures as Patterns of Passing Messages, J. Artificial Intelligence, 8(3), 323 364, 1977

[10] Anton, A. I., Goal based requirements analysis, proceedings of the IEEE International Conference on Requirements Engineering, Colorado Springs, USA, 1996

[11] Boehnlein, M., Ulbrich vom Ende A., Deriving initial DW structures from the conceptual data models of the underlying operational information systems, Proceedings of workshop on DW and OLAP, Kansas City, MO, USA, 1991

[12] Prakash, N., Gosain, A., An approach to engineering the requirements of DWs, Springer- Veralag, Requirements Eng. Journal, 2007

[13] Bresciani P., Giorgini P., Mylopoulous J., Perini A., TROPOS: An Agent-Oriented Software Development Methodology, J. Autonomous Agents and Multi-Agent Systems, 8, 203-236, 2004

[14] Giorgini, P., Rizzi, S., Garzetti, M., GRAnD: A goaloriented approach to requirements analysis in DWs, Elsevier Science Direct, Decision Support Systems, 45,421,2008 .

[15] Yu, E.S.K., Towards Modeling and Reasoning Support for Early-Phase Requirements Engineering, proceedings of IEEE International Symposium on Requirements Engineering, 226-235,1997

[16] Van, L.A., Goal-oriented requirements engineering: a guided tour. Invited paper for RE'01, proceedings of 5th IEEE international symposium on requirements engineering, Toronto, August, 249-263, 2001

[17] Inmon, W. H., Building the DW, Wiley, New York, 1996 